\title{
Significant overexpression of SPARC/osteonectin mRNA in pancreatic cancer compared to cancer of the papilla of Vater
}

\author{
KLAUS L. PRENZEL ${ }^{1}$, UTE WARNECKE-EBERZ ${ }^{1}$, HUAN XI ${ }^{1,3}$, JAN BRABENDER ${ }^{1}$, \\ STEPHAN E. BALDUS ${ }^{2}$, ELFRIEDE BOLLSCHWEILER ${ }^{1}$, CHRISTIAN A. GUTSCHOW ${ }^{1}$, \\ ARNULF H. HÖLSCHER ${ }^{1}$ and PAUL M. SCHNEIDER ${ }^{1}$ \\ ${ }^{1}$ Department of Visceral and Vascular Surgery and ${ }^{2}$ Institute of Pathology, University of Cologne, \\ Joseph-Stelzmann-Strasse 9, 50931 Cologne, Germany; ${ }^{3}$ Department of General Surgery, \\ Beijing Hospital, Da Hua Road 1, Beijing 100730, P.R. China
}

Received November 22, 2005; Accepted January 4, 2006

\begin{abstract}
Cancer of the papilla of Vater (CPV) has a significantly better outcome compared to pancreatic cancer (PC) after curative resection. Increasing evidence suggests that prognostic differences are influenced by a different tumor biology. Secreted protein acidic and rich in cystein (SPARC)/osteonectin is a multifunctional matricellular protein involved in cell-matrix interactions and might be involved in tumor pathogenesis and progression. We examined quantitative SPARC mRNA expression in CPV and PC to evaluate if varying expression might contribute to the different biologic behaviour of these entities. Quantitative real-time reverse transcription-PCR was performed to analyze expression of SPARC mRNA in a series of $31 \mathrm{PC}$ and $8 \mathrm{CPV}$ specimens and corresponding uninvolved pancreatic tissues. Relative mRNA levels (ratio tumor/normal) were calculated as (SPARC/B-actin in tumor)/(SPARC/B-actin in paired normal tissue). SPARC expression levels were associated with clinical and histopathological parameters. SPARC mRNA expression was detected in all tumor and normal tissues of the pancreas and papilla of Vater. In pancreatic cancer, 15/31 (48.4\%) patients showed overexpression of SPARC (ratio tumor/normal $>1)$ whereas in CPV only $1 / 8(12.5 \%)$ exhibited SPARC overexpression and this difference was statistically significant $(\mathrm{p}<0.05$, Mann-Whitney test). No associations were detected with $\mathrm{T}$ - and $\mathrm{N}$-categories, grading or prognosis. In conclusion, SPARC mRNA overexpression is significantly more frequent in $\mathrm{CP}$ than $\mathrm{CPV}$ and adds further evidence that $\mathrm{CP}$ and CPV are biologically different tumor entities.
\end{abstract}

Correspondence to: Dr Klaus L. Prenzel, Department of Visceral and Vascular Surgery, University of Cologne, Joseph-StelzmannStrasse 9, 50931 Cologne, Germany

E-mail: klausprenzel@hotmail.com

Key words: pancreatic cancer, papilla of Vater, secreted protein acidic and rich in cystein expression, tumor biology

\section{Introduction}

Adenocarcinoma of the pancreas (PC) is currently the fifth leading cause of cancer-related deaths in North America and Europe with rising incidence and a five-year survival rate $<5 \%$ (1-3). Although various molecular alterations were identified, which have improved our understanding for the carcinogenesis of this disease, the molecular basis for the dismal outcome of pancreatic cancer is still unknown. New treatment regimens based on molecular classifications of the individual tumor may provide improvements in outcome for patients with pancreatic carcinoma.

Cancer of the papilla of Vater (CPV) is a rare disease representing $6-12 \%$ of all periampullary malignancies (4) with an estimated incidence of 2.9 per million (5). In contrast to pancreatic cancer, it has a good prognosis with a 5-year survival rate of $>40 \%$ after curative resection $(6,7)$. Because of its anatomical localization, CPV becomes symptomatic at an earlier stage than pancreatic cancer. Therefore, most of the patients are candidates for surgical therapy. Nevertheless, there is a raising body of evidence suggesting that biological differences might also contribute to the different prognosis (8).

Secreted protein acidic and rich in cystein (SPARC) also called osteonectin belongs to a group of bone matrix-associated factors that mediate cell-matrix interactions but do not primarily serve structural roles (9). The role of SPARC in carcinogenesis has not been elucidated in detail. In human melanoma cell lines, SPARC protein overexpression is associated with invasive behavior (10), and suppression of SPARC expression by antisense RNA abrogates the tumorgenicity of these cells (11). On the other hand, SPARC protein expression in ovarian cancer cells is inversely correlated with the degree of malignancy, and overexpression induces apoptosis in cancer cells (12). Transfection of SPARC cDNA into an ovarian carcinoma cell line reduced its growth rate in culture and its ability to induce tumors in rodents (13). Transfection of SPARC cDNA into breast cancer cell lines inhibited cancer cell proliferation by slowing progression into S phase (14). Overexpression of SPARC protein or RNA has be reported in esophageal cancer (15), breast cancer (16), 


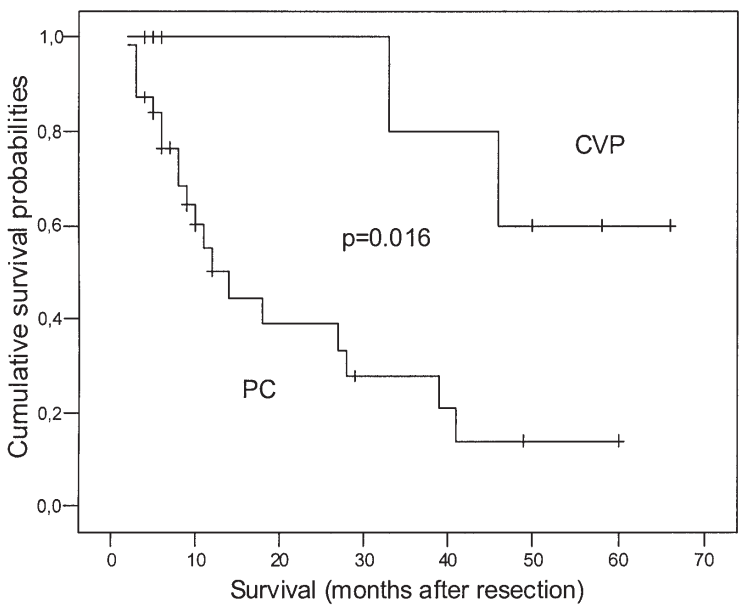

Figure 1. Kaplan-Meier survival curves of patients with pancreatic cancer (PC) $(n=31)$ and cancer of the papilla of Vater (CVP) $(n=8)$.

hepatocellular cancer (17), bladder cancer (18), and malignant melanomas (19). In pancreatic cancer, it was shown that SPARC expression is frequently lost in cell lines in conjunction with aberrant DNA methylation. Furthermore, SPARC was highly expressed by peritumoral fibroblasts and the expression of SPARC in fibroblasts was enhanced by coculture with pancreatic cancer cells. Exogenous SPARC inhibited the growth of pancreatic cancer cells in vitro (20).

We performed quantitative real-time RT-PCR assays to evaluate if SPARC is differentially expressed in $\mathrm{CP}$ versus $\mathrm{CPV}$ and if differences in SPARC expression were associated with clinico-pathological variables.

\section{Materials and methods}

Patients and specimens. Between July 1997 and December 2003 tumor and corresponding normal tissues from 63 patients, who underwent curative resection of pancreatic or ampullary tumors, were collected. Informed consent was obtained from all patients. Data and tissue collection were in accordance with the regulations of the local ethics committee.

For 31 patients with ductal adenocarcinoma of the pancreas and 8 patients with tumors of the papilla of Vater, matched tissue was available for gene analysis. The study population consisted of $24(62 \%)$ men and $15(38 \%)$ women, with a median age of 59.4 years (range, 33-81 years). All patients had adenocarcinomas. Tumor staging was performed according to the International Union Against Cancer (UICC) tumor node metastasis (TNM) classification. In patients with pancreatic cancer, one $(3.2 \%)$ was in stage I, three $(9.6 \%)$ in stage II, 24 $(77.4 \%)$ patients were in stage III, and three $(9,6 \%)$ were in stage IVa. In patients with CPV, five were in stage II, two in stage III and one patient was in stage IV.

Twenty-four patients underwent a Whipple's procedure, in 10 patients the pylorus was preserved. In four patients a left-sided pancreatic resection and in one patient a total pancreatectomy was performed. The mean follow-up for surviving patients was 9.5 months (range, 62 months) with no patient lost to follow-up.

Tissues were frozen immediately in liquid nitrogen and stored at $-80^{\circ} \mathrm{C}$ until further processing. The definitive

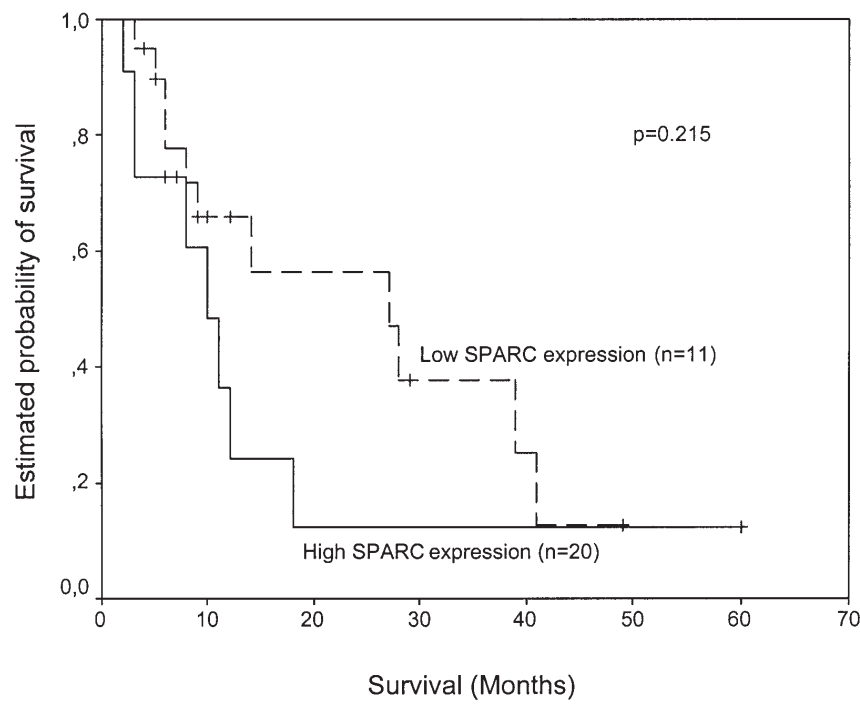

Figure 2. Estimated probability of survival of patients with pancreatic cancer showing low and high SPARC mRNA expression.

histology of the tissues used for RNA isolation was confirmed in serial sections analyzed by a staff pathologist (S.E.B.).

Quantitative RT-PCR. Total RNA was isolated using Trizol reagent (Life Technologies/Gibco, Grand Island, NY) and quantified at $\mathrm{A}_{260 / 280 \mathrm{~mm}}$ (Smart Spec; Biorad, Hercules, CA). Total cellular RNA $(0.5 \mu \mathrm{g})$ was reverse-transcribed using an oligo (dT) 18 primer and MMLV (Moloney murine leukemia virus) reverse transcriptase (Clontech Lab.; Palo Alto, USA) according to the manufacturer's recommendations. Placenta RNA from this kit was used to prepare standard curves. An amount of 25 ng of cDNA was taken for real-time PCR using the TaqMan ABI PRISM-7900HT sequence detection system (Applied Biosystems, Darmstadt). By means of fluorescence emission this technique allows to find the cycling point when the PCR product is detectable (threshold cycle). This $\mathrm{Ct}$ value correlates to the starting quantity of the target $(21,22)$. To normalize the amount of total RNA present in each reaction, the housekeeping gene $\beta$-actin was amplified.

Primers used for PCR amplification were chosen to encompass intron between exon sequences. Primers and probes were designed for full length cDNA sequences blasted against human genomic sequences to identify exon-exon junctions (NCBI), using Primer Express software (Applied Biosystems). The $B$-actin probe was labeled with 5'-VIC and 3'-minor groove binder/non-fluorescent quencher (Applied Biosystems). The SPARC probes were labeled at the 5' end with FAM and at the 3' end with the quencher TAMRA (Eurogentec, Seraing, Belgium). The sequences for the primers and probes were: SPARC sense 5' TCT TCC CTG TAC ACT GGC AGT TC 3', anti-sense 5' AGC TCG GTG TGG GAG AGG TA 3', probe 5' CAG CTG GAC CAG CAC CCC ATT GAC 3'.

Each probe was analyzed using MALDI-TOF and reliability of PCR amplification and detection was verified on serial dilutions of standard cDNAs prior to analyses of patient samples. To ensure that the genomic DNA was amplified, the assays were checked with RNA samples minus reverse transcription control as well as with genomic DNA as template. 


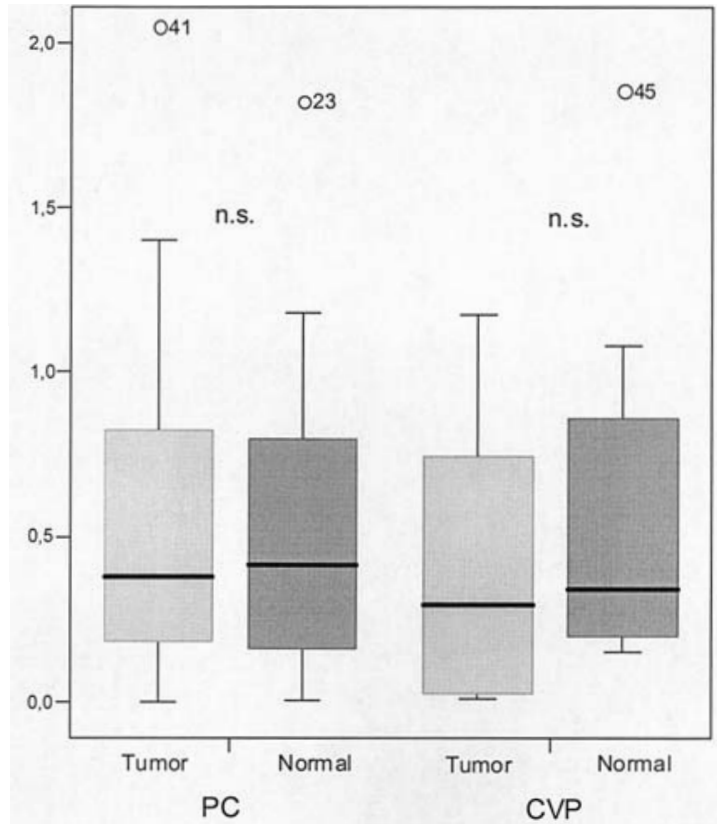

Figure 3. Median expression of SPARC in pancreatic cancer (PC) $(n=31)$ and cancer of the papilla of Vater (CVP) $(n=8)$.

The PCR reaction mixture contained $300 \mathrm{nM}$ of each primer, $200 \mathrm{nM}$ probe in a final volume of $20 \mu 1$. PCR conditions were $50^{\circ} \mathrm{C}$ for $2 \mathrm{~min}, 95^{\circ} \mathrm{C}$ for $10 \mathrm{~min}$, followed by 40 cycles at $95^{\circ} \mathrm{C}$ for $15 \mathrm{sec}$ and $60^{\circ} \mathrm{C}$ for $1 \mathrm{~min}$. Initial template was calculated from the cycle number when the amount of PCR product passed a threshold set in the exponential phase of the PCR reaction (CT-value). Relative gene expression levels were calculated using standard curves generated by serial dilutions of placenta cDNA (Clontech Lab.). All analyses were done in triplicate.

Absolute expression levels were calculated as SPARC/ $\beta$-actin in tumor and normal tissues, respectively. Relative mRNA expression levels (ratio tumor/normal) were calculated as (survivin/ß-actin in tumor)/(SPARC/ß-actin in paired normal tissue).

Statistical analysis. The gene expression analyses yield values which are expressed as ratios between two absolute measurements: the gene of interest and the internal reference gene $B$-actin. Gene expression levels were described using the median as a point estimator and the range of values. Cut-off values for discrimination of dichotomized mRNA expression levels and clinico-pathologic parameters were derived from receiver operating curve (ROC) data (area under the curve and the $95 \%$ confidence interval) according to Metz et al (23). Associations between gene expression levels and clinicopathological parameters were evaluated using the $\chi^{2}$ test for dichotomized variables, Wilcoxon rank test for paired variables and the Mann-Whitney test for independent variables applying Fisher's exact testing for significance.

Partitioning of gene expression levels to construct prognostic groups was performed according to LeBlanc and colleagues (24). Briefly, the best cut-off value for a supposed prognostic variable is determined by simulating the log-rank test for all observed covariate values within the entire data

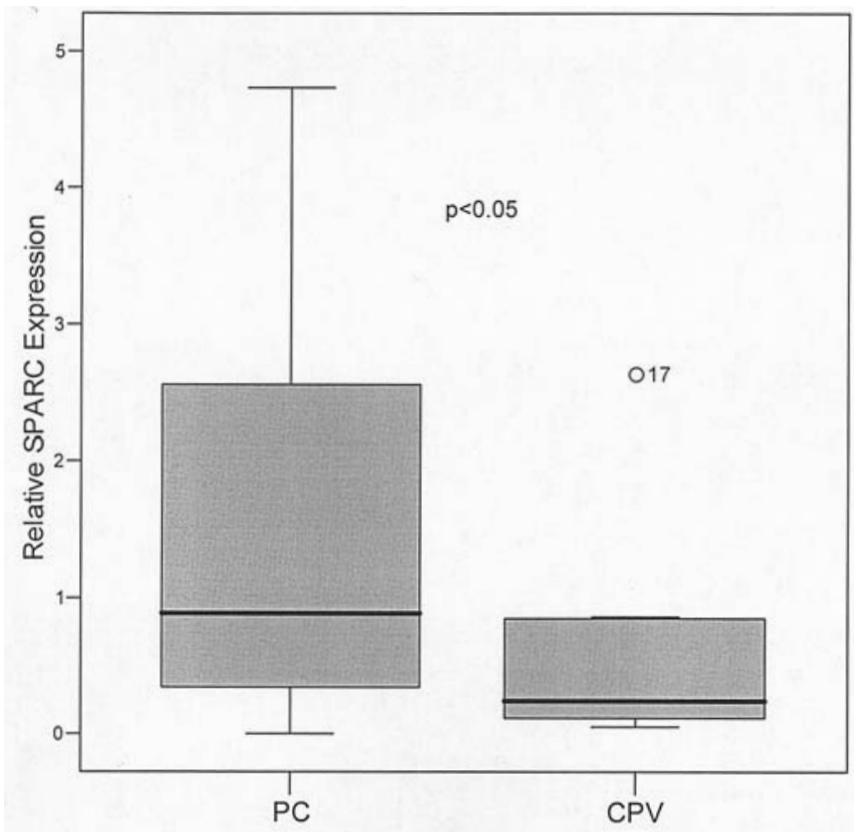

Figure 4. Relative expression (ratio tumor/normal) of SPARC mRNA in pancreatic cancer $(\mathrm{PC})(\mathrm{n}=31)$ and cancer of the papilla of Vater $(\mathrm{CVP})(\mathrm{n}=8)$

set. The minimal log-rank p-value determines the best cut-off value for dichotomization of the covariate. Kaplan-Meier (25) plots were used to describe the survival distribution and the logrank test was used to evaluate for survival differences (26).

The level of significance was set to $\mathrm{p}<0.05$ in all statistical testing. Unless otherwise specified, $\mathrm{p}$-values were given for two-sided testing.

All statistical tests were performed using the software package SPSS for Windows, version 12.0, Chicago, IL, USA.

\section{Results}

SPARC mRNA expression. Expression of SPARC mRNA was detected in all pancreatic cancer specimens, in all cancers of the papilla, and in all normal pancreatic specimens. Median SPARC gene expression was similar in tumor (0.38) and normal $(0.41, \mathrm{p}=0.35)$ pancreatic tissue. Also, in cancer of the papilla the median SPARC was similar in tumor (0.29) and normal (0.33) specimens ( $\mathrm{p}=0.12$ ) (Fig. 3).

In pancreatic cancer, 15 out of $31(48.4 \%)$ patients showed overexpression ( $\mathrm{T} / \mathrm{N}$ ratio $>1$ ) of SPARC mRNA. In contrast, only in 1 out of $8(12.5 \%)$ CPV demonstrated overexpression of SPARC mRNA. This difference was statistically significant ( $<<0.05$, Mann-Whitney test, Fig. 4).

Association of SPARC mRNA expression with clinicopathologic variables. No significant associations between gene expression levels and clinico-pathologic parameters such as UICC tumor stage, $\mathrm{pT}$ and $\mathrm{pN}$-categories, or grading of the primary tumor were observed.

mRNA expression and survival of patients with $P C$ and $C P V$. Median survival was 14 months (range 2-60 months) for patients with PC and significantly different from 39.5 months 
(range, 4-66 months) for patients with CPV ( $\mathrm{p}<0.016$ log-rank test; Fig. 1).

Partitioning of gene expression levels to construct prognostic groups according to LeBlanc and colleagues (24) did not reveal any correlation between gene expression and survival of patients with CPV. For patients with pancreatic cancer, the largest segregation between survival probabilities was obtained with a relative SPARC expression level of 2.1 ( $p=0.21$, log-rank test; Fig. 2). However, no statistical significance was reached by this segregation. Twenty patients displayed a low $(<2.1)$ and 11 patients a high $(\geq 2.1)$ SPARC gene expression. The median survival for patients with low gene expression levels was 27 months (95\% CI, 7-47 months) in contrast to 10 months (95\% CI, 6-14 months) for patients with high SPARC expression levels.

\section{Discussion}

The surgical therapy of carcinoma of the papilla of Vater and adenocarcinoma of the pancreas consists of a pylorus preserving or a classical pancreaticoduodenectomy (Whipple procedure). Despite this identical surgical approach, the longterm prognosis is different. Five-year survival rates of $0-25 \%$ for pancreatic cancer and $15-56 \%$ for CPV have been reported $(1,6)$. It was shown that a different tumor biology, represented by higher expression levels of members of the EGF-R family (EGF-R, c-erbB2 and c-erbB3) and metastasisassociated genes, contributes to the different growth patterns of these tumors $(8,27)$.

The role SPARC mRNA expression in pancreatic cancer and CPV has not been addressed so far. The overexpression of SPARC was correlated to progression, incidence of distant metastasis and survival in thin cutaneous malignant melanomas (19) and associated with worse prognosis in patients with urinary bladder cancer (18). This correlation was not found in studies examining esophageal (15) or breast cancer (16). In non-small cell lung cancer, coauthors of this study could not detect a difference in SPARC expression between malignant and normal lung tissues applying QRT-PCR (28). The results of these three studies are consistent with ours, showing no statistically significant difference in median SPARC mRNA expression between normal and malignant samples from patients with pancreatic cancer and CPV. However, SPARC overexpression $(\mathrm{T} / \mathrm{N}$ ratio $>1)$ was frequently detected $(48.4 \%)$ in pancreatic cancer compared to CPV (12.5\%) and this difference was statistically significant $(\mathrm{p}<0.05)$.

These data substantiate previous studies concerning different gene expressions between the two tumor entities $(8,27)$ and add further evidence that they represent biologically different tumor entities.

There is a trend towards longer survival in pancreatic cancer patients with low SPARC gene expression compared to patients with a high intratumoral expression. This finding is also confirmed by two studies using immunohistochemistry for detection of SPARC expression in urinary bladder cancer (18) and non-small cell lung cancer (29). Sato et al (20) have shown that SPARC mRNA was predominantly expressed in stromal fibroblasts adjacent to the neoplastic epithelium in primary pancreatic cancers. Since laser-micro-dissection was not performed in this study, we cannot rule out that one source of SPARC mRNA would be from stromal fibroblast next to tumor cells. Even if this is the case, the difference between PC and CVP would remain although the source of SPARC mRNA is not the cancer cell itself.

In summary, we have shown that overexpression of SPARC mRNA is significantly more frequent in pancreatic cancer than cancer of the papilla of Vater and this finding adds further evidence that the two entities are biologically different.

\section{References}

1. Jemal A, Murray T, Samuels A, Ghafoor A, Ward E and Thun MJ: Cancer Statistics 2003. CA Cancer J Clin 53: 5-26, 2003.

2. Fernandez E, LaVecchia C, Porta M, Negri E, Lucchini F and Levi F: Trends in pancreatic cancer mortality in Europe, 19551989. In J Cancer 57: 786-792, 1994.

3. Bramhall SDJ and Neoptolemos JP: Epidemiology of Pancreatic Cancer. Vol. 2. Blackwell Scientific, Boston, MA, pp889-906, 1998.

4. Neoptolemos JP, Talbot IC, Carr-Locke DL, Shaw DE Cockleburgh R, Hall AW and Fossard DP: Treatment and outcome in 52 consecutive cases of ampullary carcinoma. $\mathrm{Br} \mathbf{J}$ Surg 74: 957-961, 1987

5. Anderson JB, Cooper MJ and Williamson RC: Adenocarcinoma of the extrahepaic biliary tree. Ann R Coll Surg Engl 67: 139-143, 1985.

6. Beger HG, Treitschke F and Poch B: Adenocarcinoma of the ampulla of Vater - operative treatments and results. In: The Pancreas. Beger HG, Warshaw Al, Büchler MW, et al (eds). Blackwell Science, Oxford, pp1328-1331, 1998.

7. Willett CG, Warshaw AL, Convery K and Compton CC: Patterns of failure after pancreaticoduodenectomy for ampullary carcinoma. Surg Gynecol Obstet 176: 33-38, 1993.

8. Friess H, Wang L, Zhu Z, Gerber R, Schröder M, Fukuda A, Zimmermann A, Korc M and Büchler MW: Growth factor receptors are differentially expressed in cancers of the papilla vater and pancreas. Ann Surg 230: 767-775, 1999.

9. Lane TF and Sage EH: The biology of SPARC, a protein that modulates cell-matrix interactions. FASEB J 8: 163-173, 1984.

10. Kato Y, Frankenne F, Noel A, Sakai N, Nagashima Y, Koshika S, Miyazaki K and Foidart JM: High production of SPARC/ osteonectin/BM-40 in mouse metastatic B16 melanoma cell lines. Pathol Oncol Res 6: 24-26, 2000.

11. Ledda MF, Adris S, Bravo AI, Kairiyama C, Bover L, Chernajovsky Y, Mordoh J and Podhajcer OL: Suppression of SPARC expression by antisense RNA abrogates the tumorigenicity of human melanoma cells. Nat Med 3: 171-176, 1997.

12. Yiu GK, Chan WY, Ng SW, Chan PS, Cheung KK, Mok SC and Berkowitz RS: SPARC (secreted protein acidic and rich in cystein) induces apoptosis in ovarian cancer cells. Am J Pathol 159: 609-622, 2001 .

13. Mok SC, Chan WY, Wong KK, Muto MG and Berkowitz RS: SPARC an extracellular matrix protein with tumor suppressing activity in human ovarial epithelial cells. Oncogene 12: 1895-1901, 1996.

14. Dhanesuan N, Sharp JA, Blick T, Price JT and Thompson EW: Doxycycline-inducible expression of SPARC/Osteonectin/ BM40 in MDA-MB-231 human breast cancer cells results in growth inhibition. Breast Cancer Res Treat 75: 73-85, 2002.

15. Porte H, Triboulet JP, Kotelevets L, Carrat F, Prevot S, Nordlinger B, Di Gioia Y, Wurtz A, Comoglio P, Gespach C and Chastre E: Overexpression of stromelysin-3, BM-40/SPARC, and MET genes in human esophageal carcinoma: implications for prognosis. Clin Cancer Res 4: 1375-1382, 1998

16. Kim YW, Park YK, Lee J, Ko SW and Yang MH: Expression of osteopontin and osteonectin in breast cancer. J Korean Med Sci 13: 311-323, 1998.

17. Le Bail B, Faouzi S, Boussarie L, Guirouilh J, Blanc JF, Carles J, Bioulac-Sage P, Balabaud C and Rosenbaum J: Osteonectin/ SPARC is overexpressed in human hepatocellular carcinoma. J Pathol 189: 46-52, 1999.

18. Yamanaka M, Kanda K, Li NC, Fukumori T, Kanayama HO, Oka N and Kagawa S: Analysis of the gene expression of SPARC and its prognostic value for bladder cancer. J Urol 166: 2495-2499, 2001. 
19. Massi D, Franchi A, Borgognoni L, Reali UM and Santucci M: Osteonectin expression correlates with clinical outcome in thin cutaneous malignant melanomas. Hum Pathol 30: 339-344, 1999.

20. Sato N, Kukushima N, Maehara N, Matsubayashi H, Su GH, Koopmann J, Hruban RH and Goggins M: SPARC/Osteonectin is a frequent target for aberrant methylation in pancreatic adenocarcinoma and mediator of tumor-stromal interactions. Oncogene 22: 5021-5030, 2003.

21. Heid CA, Stevens J, Livak KJ and Williams PM: Real-time quantitative PCR. Genome Res 6: 986-994, 1996.

22. Gibson UE, Heid CA and Williams PM: A novel method for real time quantitative RT-PCR. Genome Res 6: 995-1051, 1996.

23. Metz CE, Goodenough DJ and Rossmann K: Evaluation of receiver operating characteristic curve data in terms of information theory, with applications in radiography. Radiology 109: 297-303, 1973.

24. LeBlanc M, Jacobson J and Crowley J: Partitioning and peeling for constructing prognostic groups. Stat Methods Med Res 11: 247-274, 2002.

25. Kaplan EL and Meier P: Nonparametric estimation from incomplete observations. J Am Stat Assoc 153: 187-220, 1958.
26. Mantel N: Evaluation of survival data and two new rank order statistics arising in its consideration. Chemother Rep 50: 163-170, 1966.

27. Friess H, Guo X-Z, Tempia-Caliera AA, Martignoni ME, Fukuda A, Zimmermann A, Korc M and Büchler MW: Differential expression of metastasis-associated genes in papilla of Vater and pancreatic cancer correlates with disease stage. J Clin Oncol 19: 2433-2432, 2001.

28. Schneider S, Yochim JM, Brabender J, Uccida K, Danenberg KD, Metzger R, Schneider PM, Salonga D, Hölscher AH and Danenberg PV: Osteopontin but not osteonectin messenger RNA expression is a prognostic marker in curatively resected non-small cell lung cancer. Clin Cancer Res 10: 1588-1596, 2004.

29. Koukourakis MI, Giatromanolaki A, Brekken RA, Sivridid E, Gatter KC, Harris AL and Sage EH: Enhanced expression of SPARC/Osteonectin in the tumor-associated stroma of nonsmall cell lung cancer is correlated with markers of hypoxia/ acidity and with poor prognosis of patients. Cancer Res 63: 5376-5380, 2003. 